\title{
Asbestosis, laryngeal carcinoma, and malignant peritoneal mesothelioma in an insulation worker
}

\author{
Alf Fischbein, Jiin-Chyuan J Luo, Glen R Pinkston
}

\begin{abstract}
Asbestos associated diseases consist of both benign and malignant conditions. A rare constellation of asbestosis, laryngeal carcinoma, and malignant peritoneal mesothelioma occurring in a patient with long term occupational exposure to airborne asbestos fibres is presented. The observation illustrates the powerful disease-causing potential of occupational exposure to asbestos. A brief discussion of multiple primary neoplasms associated with exposure to asbestos is also presented.
\end{abstract}

Asbestos associated diseases continue to pose a major public health problem in the United States. ${ }^{1}$ They include both benign disorders, such as asbestosis and asbestos related pleural abnormalities, and malignant conditions. The malignant group of disorders is represented primarily by lung cancer and malignant pleural or peritoneal mesothelioma. Epidemiological investigations have suggested that other neoplasms may also be associated with a history of exposure to airborne asbestos fibres. These include certain gastrointestinal neoplasms as well as cancer of the larynx. ${ }^{2}$ The increased risk of developing lung cancer among people exposed to asbestos is widely considered to be a synergistic effect between cigarette smoking and exposure. ${ }^{3}$ In this context, multiple aetiological factors, such as cigarette smoking, alcohol intake, and exposure to asbestos have also been suggested for cancer of the larynx. ${ }^{4}$

We report on a patient with pulmonary asbestosis who developed cancer of the larynx followed three months later by the clinical onset of malignant

Division of Environmental and Occupational Medicine, Department of Community Medicine, the Mount Sinai School of Medicine of the City University of New York, New York, New York 10029, USA

A Fischbein, J-C J Luo

Department of Pathology, Halifax Hospital Medical Center, Daytona Beach, Florida, USA (present affiliation: Jackson Hospital and Clinic, Montgomery, Alabama 36106, USA).

G R Pinkston peritoneal mesothelioma. A brief review of multiple primary cancers occurring among asbestos exposed populations is also presented.

\section{Case report}

CLINICOPATHOLOGICAL SUMMARY

The patient was a man born in 1921. His medical history was non-contributory except for two episodes of atrial flutter in 1973 and in 1975 . In July 1982 the patient developed hoarseness. His voice returned to normal, but during the summer of 1983 it became worse again, with hoarseness and phonasthenia. A weight loss of around 15 pounds occurred during the summer months of 1983. He was admitted to hospital for evaluation in August 1983. Laryngoscopy showed an exophytic lesion along the right vocal cord, which had well preserved motion. Biopsy was performed and histopathological analysis showed infiltrating well differentiated squamous cell carcinoma of the right vocal cord.

In December 1983 the patient noticed distention of the abdomen. Evaluation with upper gastrointestinal series was essentially unremarkable. A computed tomography scan of the pancreas and a liver scan were also within normal limits. Cholecystography and an intravenous pyelogram were also normal. Paracentesis fluid cytology was not diagnostic of malignancy. Exploratory laparotomy showed considerable ascites and generalised intra-abdominal tumour spread. The omentum was largely replaced by tumour and innumerable tumour nodules of varying size were implanted on the peritoneal surfaces. Histopathological examination of an omental biopsy showed diffuse peritoneal mesothelioma exhibiting a tubulopapillary growth pattern characterised by fibrous stromal cores covered by polygonal to columnar mesothelial cells exhibiting moderate nuclear pleomorphism. In January 1984, ascites recurred and an additional tap of four litres was done. The patient experienced a rapidly progressive clinical course and died in May 1984.

Post mortem examination disclosed residual, locally infiltrating squamous carcinoma in the right vocal cord. The lungs were encased by partially confluent, focally calcified pleural plaques, predominantly embodying the visceral and parietal surface of the lower lobes and hemidiaphragms. 
Considerable interstitial fibrosis, emphysematous changes, and severe necrotising bronchopneumonia were present bilaterally. The abdominal cavity exhibited diffuse peritoneal mesothelioma with replacement of the omentum and extensive peritoneal studding of the spleen, gastrointestinal tract, pancreas, liver, diaphragm, and abdominal walls. Asbestos bodies were identified in both lungs, but were not seen in either tumour. No evidence of metastatic carcinoma was found. Mesothelioma was not identified in the thoracic cavity.

Review of a series of chest radiographs taken between December 1980 and August 1983 showed extensive parenchymal scarring graded as $s / t 2 / 3$ according to the International Labour Office International Classification of Radiographs of Pneumoconioses. ${ }^{5}$ Pleural abnormalities consisted of bilateral thickening of the lateral costal pleura graded as b3 on the right side and as b2 on the left side with calcifications in the thickened pleura and on the domes of the hemidiaphragms (figure).

\section{OCCUPATIONAL HISTORY}

The patient had worked as an insulator between 1942 and 1973. During these years he had routinely handled insulation materials containing asbestos. He applied thermal insulation to pipes and pressure vessels and removed old thermal insulation materials. He was employed in shipyards, paper-

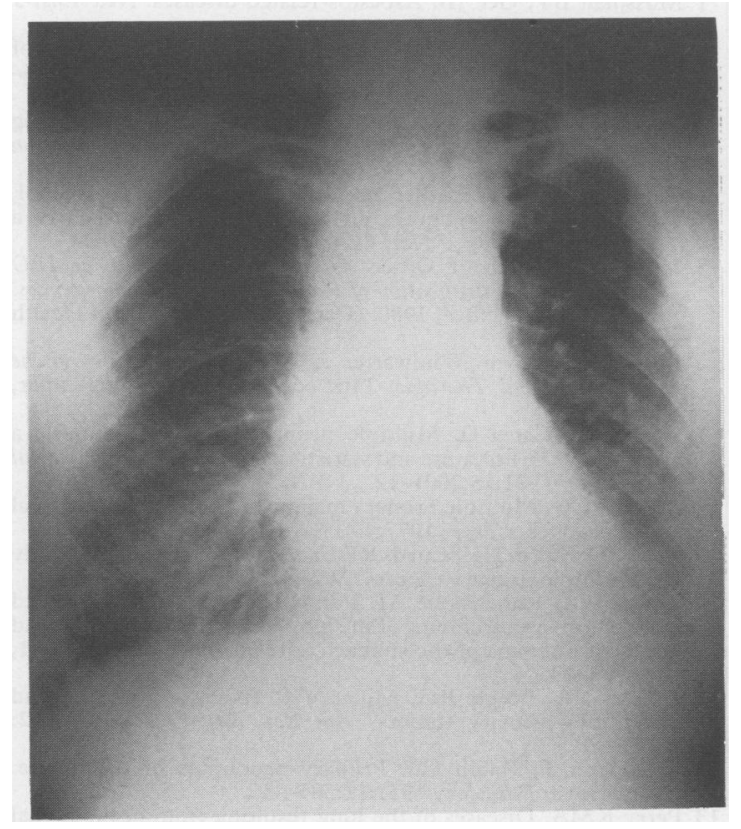

Chest radiograph of patient with laryngeal cancer and peritoneal mesothelioma showing interstitial lung disease (asbestosis), pleural thickening, and calcifications. mills, powerhouses, and various other industrial facilities. Thus he had a history of potential for appreciable exposure to airborne materials containing asbestos during several years.

The patient smoked 30 cigarettes a day between 1936 and 1967. He smoked cigars between 1967 and 1981 and chewed tobacco for most of his adult life. He drank some six cans of beer a day for several years.

\section{Discussion}

The reported case shows the potential for the development of multiple diseases after occupational exposure to airborne asbestos fibres. The patient manifested pulmonary asbestosis, laryngeal cancer, and peritoneal mesothelioma. The last disorder became clinically evident three months after the diagnosis of the first malignancy. Both malignant diseases developed, characteristically, some 40 years after the onset of employment in the asbestos related trade.

The potential health consequences after occupational exposure to asbestos have been studied in detail in clinical and epidemiological investigations as mentioned above. ${ }^{1-3}$

Multiple primary malignant neoplasms in general were described in case reports by Billroth and von Winiwarter. ${ }^{6}$ They reported patients with both cutaneous and gastrointestinal malignancies, which were independent of each other. Warren and Gates found 1259 patients from published reports, who had reasonably well documented multiple primary malignancies. These workers also suggested diagnostic criteria for multiple primary neoplasms-namely, that each of the tumours must present a definite picture of malignancy, that each lesion must be distinct, and that the probability that one is a metastatic lesion from the other must be excluded. ${ }^{7}$ Classification systems for multiple primary neoplasms in terms of site and tissue of origin have also been established. ${ }^{8}$ Various aetiological factors including environmental, endocrine, and genetic risk factors have been suggested for multiple primary cancers and related to specific organ systems. ${ }^{9}$

In 1961, Telischi and Rubenstone reported a case of pulmonary asbestosis with squamous cell carcinoma of the lung, bronchial adenoma, and adenocarcinoma of the stomach. ${ }^{10}$ This is, to our knowledge, the first reported case of multiple primary cancers in an asbestos exposed patient. Subsequently, Dohner et al reported five asbestos exposed patients with multiple primary tumours. Two patients had lung carcinoma and colon carcinoma and three others had two distinct pulmonary carcinomas. ${ }^{11}$ Selikoff et al reported the presence of multiple cancers in $48(2 \%)$ of 2271 deaths among insulators. ${ }^{3}$ The simultaneous occurrence of peritoneal mesothelioma and laryngeal cancer as separate entities was not reported in this large scale popula- 
tion study, and we have been unable to document a previously reported case.

With regard to aetiological considerations for the development of these disorders in this particular patient the following considerations are presented.

Although mesothelioma was clarified as a clinicopathological entity in $1931^{12}$ and "endothelioma of the pleura" was reported in asbestos workers in $1947,{ }^{13}$ it was in 1960 that Wagner et al reported cases with malignant mesothelioma on a population basis related to occupational and environmental exposure to asbestos. ${ }^{14}$ Several epidemiological studies have subsequently established a strong association between mesothelioma and exposure to asbestos. A long period of latency, usually 30 or 40 years, between initial exposure to asbestos and the development of mesothelioma is characteristically noted. Mesothelioma has a high malignant potential, and local invasion and metastases are common sequelae. The survival time after diagnosis usually does not exceed one year. ${ }^{15}$

Association between exposure to asbestos and laryngeal cancer has been reported. ${ }^{16-18}$ Doll and Peto also reviewed some case-control and cohort studies of laryngeal cancer risk in asbestos workers. In casecontrol studies, the relative risk has been reported to be between 0.8 and 14.5 , whereas in cohort studies the relative risk ranged between $0 \cdot 6$ and $2 \cdot 7$. Based on the evidence in their review, the authors concluded that asbestos should be regarded as one of the causes of laryngeal cancer. ${ }^{19}$ Tobacco and alcohol are considered to be important aetiological factors in the development of laryngeal cancer. ${ }^{4}$

Chan and Gee conducted a critical analysis of the available epidemiological investigations on the causal relation between exposure to asbestos and laryngeal cancer. They reviewed nine case-control studies and 12 cohort studies and concluded that the available epidemiological evidence did not support a causal association between exposure to asbestos and laryngeal cancer because significant associations did not remain after adjusting for smoking and alcohol consumption. ${ }^{20}$

In a recent study of laryngeal cancer in Denmark based on register linkage data, smoking and alcohol habits did not fully explain the variation in risk. The suggestion was made that, as well as marital state, occupational factors including asbestos should be considered. ${ }^{21}$ An analysis by Smith $e t$ al of data from published cohorts or subcohorts of sufficient size from populations with substantial exposure to asbestos, concluded that asbestos is a probable cause of laryngeal carcinoma. ${ }^{22}$ On the other hand a very weak link between asbestos and laryngeal cancer was the conclusion presented by Liddell in a recent editorial. ${ }^{23}$

Although a causal relation between asbestos exposure and laryngeal cancer is suggested by several studies, great variations in risk assessment exist between different investigations.

We had little reason, in the present case, to question the association between the malignant mesothelioma and the history of occupational exposure to asbestos, particularly in the presence of severe asbestosis. Regarding the laryngeal cancer, we suggest that tobacco smoking, alcohol consumption, and asbestos exposure were all likely contributory factors.

Our patient developed pulmonary asbestosis, laryngeal cancer, and malignant peritoneal mesothelioma after considerable exposure to airborne dust containing asbestos over three decades. The constellation of all three diseases in one person appears to be very uncommon. Although the observation in one case can be a random event, we believe that the asbestos related epidemiological features of these diseases permit us to suggest this case report as an illustration of the powerful disease-causing potential of occupational exposure to asbestos.

Requests for reprints to: Alf Fischbein, MD, Division of Environmental and Occupational Medicine, Department of Community Medicine, Mount Sinai School of Medicine of the City University of New York, One Gustave L Levy Place, New York, New York 10029, USA.

1 Mossman BT, Gee JB. Asbestos-related diseases. New Engl J Med 1989;320:1721-30.

2 Selikoff IJ, Hammond EC, Seidman H. Mortality experience of insulation workers in the United States and Canada, 19431976. Ann N Y Acad Sci 1979;330:91-116.

3 Selikoff IJ, Hammond EC, Churg J. Asbestos exposure, smoking and neoplasia. Journal of the American Medical Association 1968;204:106-12.

4 Burch D, Howe GR, Miller AB, Semenciw R. Tobacco, alcohol, asbestos, and nickel in the etiology of cancer of the larynx: a case-control study. J Natl Cancer Inst 1981;67:1219-24.

5 International Labour Office. Guidelines for the use of ILO International Classification of Radiographs of Pneumoconioses. Geneva: ILO Office, 1980. (Occupational Safety and Health Series No 22.)

6 Billroth CAT, von Winiwarter A. Die allgemeine chirurgische Pathologie und Therapie. 14th ed. Berlin: George Reimer, 1989:908.

7 Warren S, Gates O. Multiple primary malignant tumors: a survey of the literature and statistical study. American Journal of Cancer 1931;15:2001-12.

8 Moertel CG. Multiple primary malignant neoplasms: historical perspectives. Cancer 1977;40:1786-92.

9 Boice JD, Storm HH, Curtis RE, et al. Introduction to the study of multiple primary cancers. NCI Monogr 1985;68:3-9.

10 Telischi M, Rubenstone AI. Pulmonary asbestosis associated with primary carcinoma of the lung, bronchial adenomas, and adenocarcinoma of the stomach. Archives of Pathology 1961; 72:234-43.

11 Dohner VA, Beegle RG, Miller WT. Asbestos exposure and multiple primary tumors. Am Rev Respir Dis 1975;112: 181-99.

12 Klemperer P, Rabin CB. Primary neoplasms of the pleura. Archives of Pathology 1931;11:385-412.

13 Perry KMA. Diseases of the lung resulting from occupational dusts other than silica. Thorax 1947;2:91-120. (Illustrations 75-90, reference is made to a patient of Dr $H$ Wyers.)

14 Wagner JC, Sleggs CA, Marchand P. Diffuse pleural mesothelioma and asbestos exposure in the Western Cape Province. Br J Ind Med 1960;17:260-71. 
15 Kittle CF. Mesothelioma: diagnosis and management. Chicago: Yearbook Medical Publishers, Inc, 1987.

16 Stell PM, McGill T. Asbestos and laryngeal carcinoma. Lancet 1973;ii:416-7.

17 Rubino GF, Piolatto G, Newhouse ML, Scansetti G, Aresini GA, Murray R. Mortality of chrysotile asbestos workers at the Balangero mine, northern Italy. Br J Ind Med 1979;36:187-94

18 Hillerdal G, Lindholm CE. Laryngeal cancer and asbestos. ORL J Otorhinlaryngol Relat Spec 1980;42:233-41.

19 Doll R, Peto J. Other asbestos-related neoplasms. In: Antman K, Aisner J, eds. Asbestos-related malignancy. Orlando, Florida: Grune and Stratton, 1986;81-96.

20 Chan CK, Gee BL. Asbestos exposure and laryngeal cancer: an analysis of the epidemiologicl evidence. $J$ Occup Med 1988; 30:23-7.

21 Guenel P, Engholm G, Lynge E. Laryngeal cancer in Denmark: a nationwide longitudinal study based on register linkage data. Br J Ind Med 1990;47:473-9.

22 Smith AH, Handley MA, Wood R. Epidemiological evidence indicates asbestos causes laryngeal cancer. J Occup Med 1990; 32:499-507.

23 Liddell FDK. Laryngeal cancer and asbestos. Br J Ind Med 1990;47:289-91.

Accepted 1 October 1990 